\title{
A noção de transmissão hereditária do poder nas titulaturas dos Ptolomeus
}

\author{
José das Candeias SALES
}

Los elementos que constan en los nombres de la titulatura de los Ptolomeos reflejan una profunda teoría cultural y representan un verdadero receptáculo de conceptos e ideas de enorme significado y valor históricoideológico. A través de su estudio podemos aislar una serie de indicaciones sobre las componentes del concepto monárquico vigente entre los siglos III y I a.C.

En este texto, intentamos demostrar que la más importante diferencia y característica del protocolo de los Ptolomeos en relación con el de otros faraones del Egipto antiguo es el particular énfasis puesto en la cuestión de lo hereditario carnal como vector esencial en la transmisión del poder político.

\section{The notion of hereditary transmission of power in the Ptolemaic titulatures}

The elements of the Ptolemies' protocol names reflect a deep cultural conceptualization and represent an authentic repository of concepts and ideas which have enormous significance and historical-ideological value. By studying these names, one can isolate information about components of the monarchic concept in use between the centuries III and I BC.

In this paper, we shall demonstrate that the most important difference and characteristic of the Ptolemies' protocol, when compared with protocols used by other ancient Egyptian pharaohs, relies on the particular emphasis placed on the question of bloodline, seen as an essential vector in the transmission of political power.

KEY WORDs: ptolemaic titulatures, political power

$\mathrm{O}$ s elementos constantes nos Nomes do protocolo dos Ptolomeus reflectem uma profunda conceptualização civilizacional e representam um verdadeiro repositório de conceitos, ideias e valores de enorme significado históricoideológico.

A cuidadosa selecção e utilização desses elementos era um processo discutido e ponderado em que participavam, além do soberano, sacerdotes, altos funcionários e destacados membros da família real, cabendo naturalmente aos sacerdotes egípcios autóctones, como sempre acontecera, a maior quota-parte na sua definição e estruturação devido aos profundos conhecimentos que detinham do passado egípcio e da tradição faraónica ${ }^{1}$.

A titulatura dos Ptolomeus, mais ou menos original e criativa, a exemplo da dos faraós nativos de outras épocas anteriores e posteriores, constituiu um assunto de considerável relevância,

1. Bonhême, 1987: 12.

Fecha de recepción: 12 de enero de 2007

Fecha de aceptación: 25 de junio de 2007 
condensando os Nomes escolhidos completos programas histórico-ideológicos de existência e de actuação ${ }^{2}$. Através do seu estudo, podemos isolar uma série de preciosas indicações sobre as componentes do conceito monárquico existente em determinado momento histórico ou, pelo menos, dos desejos ideológicos para eles canalizados, designadamente pelos sacerdotes ${ }^{3}$.

Antes de mais, não podemos esquecer que a dinastia lágida é geneticamente estrangeira e que a sua implantação no território egípcio necessitou do empenhado contributo dos guardiões da memória e dos protocolos que eram os próprios sacerdotes e que, neste sentido, a questão da herança, da descendência/ascendência, era fulcral simultaneamente para os quadros mentais egípcios e macedónicos ${ }^{4}$.

Neste trabalho interessa-nos, pois, considerar a titulatura dos Ptolomeus sobretudo com o objectivo de avaliarmos o peso e a importância conferidos à noção de transmissão hereditária do poder.

A partir dos informes atestados até hoje ${ }^{5}$, é possível estabelecer o seguinte quadro-geral das titulaturas faraónicas dos soberanos da dinastia lágida, de acordo com existência de fórmulas concretas que se refiram ao elemento hereditário no Nome de Hórus, no Nome das Duas Senhoras, no Nome de Hórus de Ouro e no Praenomen:

\begin{tabular}{l|l|l|l|l} 
Faraó & Nome de Hórus & $\begin{array}{l}\text { Nome das Duas } \\
\text { Senhoras }\end{array}$ & $\begin{array}{l}\text { Nome de Hórus } \\
\text { de Ouro }\end{array}$ & $\begin{array}{l}\text { Nome de Trono } \\
\text { - Praenomen }\end{array}$ \\
\hline Ptolomeu II Filadelfo & & & $\sqrt{ } 6$ & \\
\hline Ptolomeu III Evérgeta I & $\sqrt{ } 7$ & & & $\sqrt{8}$ \\
\hline Ptolomeu IV Filopator & $\sqrt{ } 9$ & & & $\sqrt{10}$ \\
\hline Ptolomeu V Epifânio & $\sqrt{ } 11$ & & & $\sqrt{12}$ \\
\hline Ptolomeu VI Filometor & & $\sqrt{13}$ & & $\sqrt{14}$ \\
\hline Ptolomeu VIII Evérgeta II & $\sqrt{15}$ & & & $\sqrt{16}$ \\
\hline Ptolomeu IX Sóter II & & $\sqrt{17}$ & & $\sqrt{18}$ \\
\hline Ptolomeu X Alexandre I & $\sqrt{19}$ & & & $\sqrt{20}$ \\
\hline Ptolomeu XII Neos Dionisos & $\sqrt{ } 21$ & & $\sqrt{22}$ & $\sqrt{23}$ \\
\hline Cleópatra VII & $\sqrt{ } 24$ & & & \\
\hline Ptolomeu XV & & & & $\sqrt{25}$
\end{tabular}

2. Cf. Kaplony, 1980: col. 641- 659; Aufrère, 1982: 19-73; Grenier, 1987: 81-104; Grenier, 1989; Barta, 1989: 11-137; Meulenaere, 1991: 53-58; Parent, 1992: 347-354; Dobrev, 1993: 179-204; Leprohon, 1996: 165-171; Spieser, 2000; Serrano Delgado, 2001: 175-184.

3. Valbelle, 1988: 22.

4. Cf. Hölbl, 2001; Schneider, 1996.

5. Como referências bibliográficas-base para a consideração da titulatura faraónica dos Lágidas e elaboração do quadro que se segue usámos: Gauthier, 1907; Beckerath, 1984: 117-123, 285-295; Beckerath, 1999: 232-247; Kurth, 1982: cols. 1193-1197.

6. shî.n-sw it.f, "Aquele que surgiu no lugar de seu pai”.

7. $h k n-n \underline{t} r w$-rmt $-h r . f m$-šsp.f-nsyt-m-it.f, “Aquele que agrada aos deuses e aos homens por ter recebido a realeza através de seu pai".

8. iw``n-ntrwy-snwy stp-(n)-R` shm-n-`nh-n-Imn, "O herdeiro dos Deuses Irmãos, o escolhido de Ré, imagem viva de Amon".

9. hwwnw-kni sḩi.n-sw it.f, “O jovem valoroso, aquele que surgiu no lugar de seu pai”. 
Duas primeiras observações globais do quadro elaborado, em relação à existência de "referências familiares":

1) Ptolomeu II Filadelfo é historicamente o primeiro faraó da Casa Real lágida a integrar na sua titulatura uma alusão directa à herança recebida do pai. A partir daí, todos os soberanos de destaque da dinastia lágida integraram nos seus Nomes (quase sempre, simultaneamente, em dois ${ }^{26}$ ) esta vertente da hereditariedade.

2) Os Nomes de Hórus e os Praenomina são os Nomes do protocolo que maior atenção conferem a esta noção de transmissão hereditária do poder.

No caso dos Praenomina, quase todos os faraós utilizaram este Nome para destacarem o elemento hereditário (no total: 9). Desses, em termos de ocorrências absolutas, alguns têm mais do que uma forma atestada (Ptolomeu XII apresenta quatro formas e os seus congéneres anteriores Ptolomeu VI, Ptolomeu IX e Ptolomeu X duas cada um). É, neste sentido, o elemento mais prolixo da onomástica lágida a englobar elementos relativos à questão hereditária.

Passemos agora a uma análise formal de pormenor dos vários Nomes dos Lágidas, onde se constatam as referências referidas. Em relação ao Nome de Hórus dos Ptolomeus, pode afirmar-se que ele é atravessado por uma indelével concepção de que a delegação e o exercício da realeza são dois vectores resultantes de uma dupla atribuição: a herança carnal e a aprovação divina.

No que diz respeito à noção de transmissão hereditária, ela é, de facto, muito forte no Nome de Hórus dos Lágidas ${ }^{27}$, designadamente nos seguintes casos:

10. iw'-n-ntrwy-mnhwy stp-(n)-Pth wsr-k3-R` shm-`nh-(n)-Imn, "O herdeiro dos Deuses Benfeitores, o escolhido de Ptah, poderoso é o ka de Ré, imagem viva de Amon".

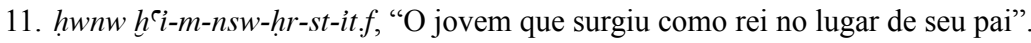

12. iw`-n-ntrwy-mr(w)y-it stp-(n)-Pth wsr-k3-R`shm-`nh-(n)-Imn, "O herdeiro dos Deuses que amam o pai, o escolhido de Ptah, poderoso é o $k a$ de Ré, imagem viva de Amon".

13. $m$-M ${ }^{\top} t$ sh'i.n-sw it.f, "Aquele que surgiu no lugar de seu pai com/ em Justiça".

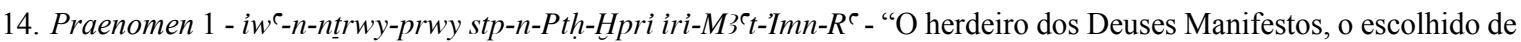
Ptah-Khepri, aquele que faz reinar a justiça de Amon-Ré”; Praenomen 2 - iwe-n-ntrwyprwy stp-n-Pth iri-M3`t-n-Imn$R^{\mathrm{e}}-r-n h h$, "O herdeiro dos Deuses Manifestos, o escolhido de Ptah, aquele que faz reinar a justiça de Amon-Ré pela eternidade".

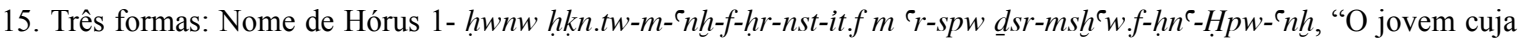
vida na realeza de seu pai é agradável, aquele que é bem sucedido nos seus actos, que se distingue no seu nascimento

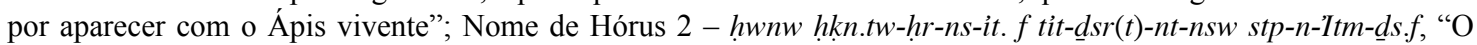
jovem cuja vida na realeza de seu pai é agradável, imagem sagrada do rei dos deuses, imagem viva do próprio Atum";

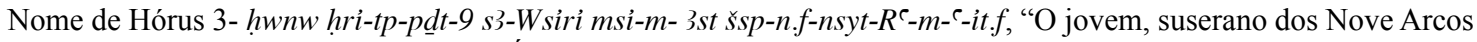
(= inimigos), filho de Osíris, nascido de Ísis, que recebeu a realeza de Ré através de seu pais.

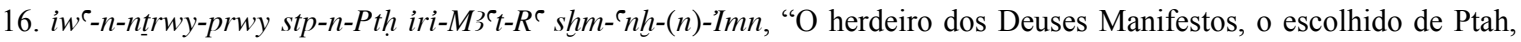
aquele que faz reinar a justiça de Ré, imagem viva de Amon”.

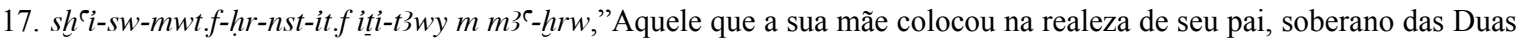
Terras, o justificado".

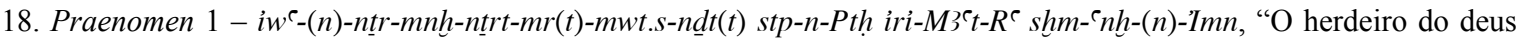
benfeitor e da deusa benfeitora, que ama a sua mãe, o salvador, o escolhido de Ptah, aquele que faz reinar a justiça de

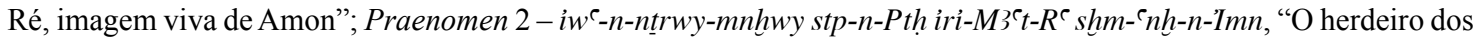
Deuses Benfeitores, o escolhido de Ptah, aquele que faz reinar a justiça de Ré, imagem viva de Amon”. 
- $m$-šsp.f-nsyt-m ${ }^{c}$-it.f, "aquele que recebeu a realeza através de seu pai” (Ptolomeu III) ${ }^{28}$;

- sh'i.n-sw it.f, "aquele que surgiu no lugar de seu pai" (Ptolomeu IV);

- hri-m-nsw-ḥr-st-it.f, "aquele que surgiu como rei no lugar de seu pai" (Ptolomeu V);

- hrr-nst-it.f, "na realeza de seu pai” (Ptolomeu VIII: Nome de Hórus 1 e Nome de Hórus 2);

- nsyt-Re-m-`it.f, "recebeu a realeza de Ré através de seu pai" (Ptolomeu VIII: Nome de Hórus 3);

- sḩi.n-sw-mwt.f-hr-nst-it.f, "aquele que a mãe colocou na realeza de seu pai" (Ptolomeu X) ${ }^{29}$;

- $t h n-m s w(t)-h r-n s t-i t . f$, "brilhando na realeza de seu pai” (Ptolomeu XII);
- twt-n-it-s, "imagem sagrada de seu pai" (Cleópatra VII).

A unidade minimal composta $h r$-nst-it.f ou as suas equivalentes $n$-sw it.f, hr-st-it.f e $n s y t$-...-it.f, integra, portanto, os Nomes de Hórus de vários Ptolomeus: Ptolomeu III, Ptolomeu IV, Ptolomeu V, Ptolomeu VIII, Ptolomeu X e Ptolomeu $\mathrm{XII}^{30}$. A ênfase comum vai, notoriamente, para it.f, "de seu pai”. Neste particular, Cleópatra VII é muito mais "modesta", sendo considerada apenas "imagem sagrada de seu pai" (twt-n-it-s).

Ptolomeu VI Filometor e Ptolomeu IX Sóter II são os únicos reis da dinastia lágida que convocaram a noção de hereditariedade do poder para o Nome das Duas Senhoras.

No caso de Ptolomeu IX, a forma encontrada numa das designações do seu Nome das Duas Senhoras, shri-sw-mwt.f-hrr-nst-it.f iți-t3wy $m$ $m 3^{C}-h r w$, "aquele que a sua mãe colocou na realeza de seu pai, soberano das Duas Terras, o jus-

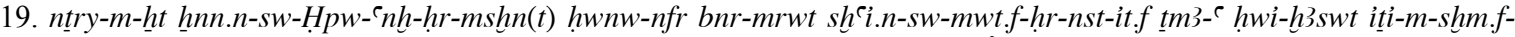
$m i-R^{\top}-p s \underline{d} . f-m$-3ht, "Divino no seu corpo, aquele que está associado com o Ápis vivente sobre os seus tijolos de nascimento, jovem perfeito, puro de amor, aquele que a mãe colocou na realeza de seu pai, de braço poderoso, que derrota as terras estrangeiras, aquele que, como Ré, ilumina o horizonte com o poder das suas conquistas".

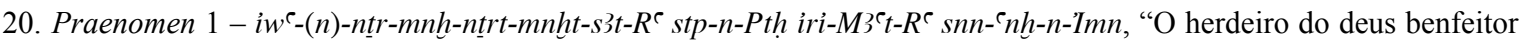
e da deusa benfeitora, filha de Ré, o escolhido de Ptah, aquele que faz reinar a justiça de Ré, imagem viva de Amon";

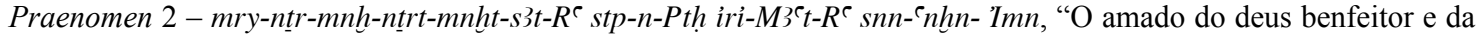
deusa benfeitora, filha de Ré, o escolhido de Ptah, aquele que faz reinar a justiça de Ré, imagem viva de Amon".

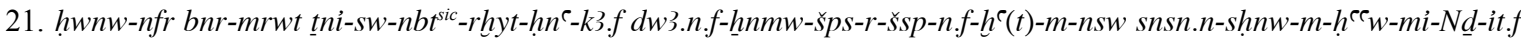

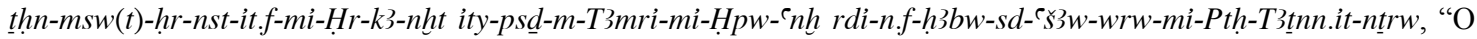
jovem perfeito, puro de amor, cujo $k a$ foi distinguido pelo povo das Duas Senhoras, que o adorável Khnum venera tanto que recebeu a coroa e surgiu como rei, aquele que se uniu a si próprio com as obras de seu pai, em alegria, aquele que brilha na realeza de seu pai como Hórus, o touro vitorioso, soberano que ilumina a Terra Amada como o Ápis vivente, a quem foram concedidos muitos festivais-sed por intermédio de Ptah-Tatjenen, o pai dos deuses".

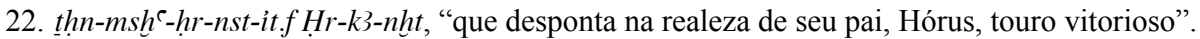

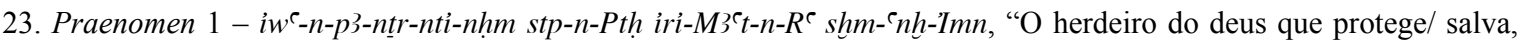
o escolhido de Ptah, aquele que faz reinar a justiça de Ré, imagem viva de Amon"; Praenomen 2 - iwe-n-p3-ntr-nti$n h m$ stp-n-Pth iri-M ${ }^{`} t$-Imn-R`, "O herdeiro do deus que protege/ salva, o escolhido de Ptah, aquele que faz reinar a

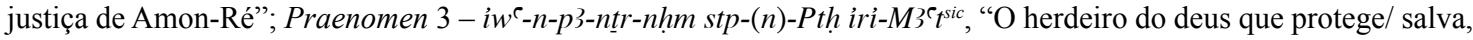

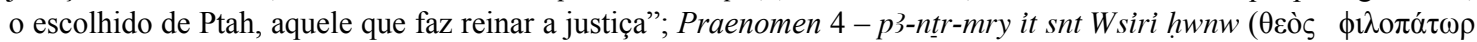

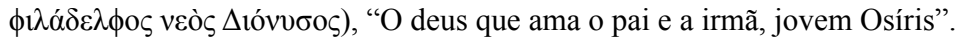

24. wrt twt-n-it-s, "A grande, imagem sagrada de seu pai".

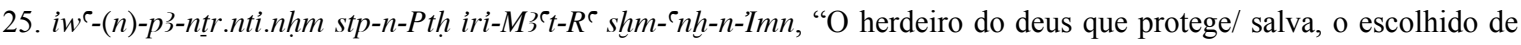
Ptah, aquele que faz reinar a justiça de Ré, imagem viva de Amon". 
tificado", refere-se ao seu primeiro reinado (116110 a.C.), tal como atesta a expressão $m w t . f$, "a sua mãe", numa clara alusão a Cleópatra III, com quem dividiu a realeza. A fórmula $s h{ }^{\lceil i}-s w$ $m w t . f-h r$-nst-it, "aquele que a mãe colocou na realeza de seu pai" usada por Ptolomeu IX será depois retomada por Ptolomeu X no seu Nome de Hórus, como vimos.

Também Ptolomeu VI Filometor, que, pelo seu Nome das Duas Senhoras, é sḩi.n-sw it.f, "aquele que surgiu no lugar de seu pai", recupera uma fórmula (sh'i.n-sw it.f) antes dele usada, como detectamos, no Nome de Hórus de Ptolomeu IV.

Estas analogias inter-textuais dos protocolos dos Lágidas permitem perceber que o traço da herança carnal ou da noção de transmissão hereditária da realeza de pai para filho é uma componente muito comum, quase obrigatória, nas suas titulaturas, embora possa flutuar entre os vários Nomes de um mesmo faraó ou de um faraó para outro.

Um dos Nome de Hórus de Ouro conhecido de Ptolomeu XII Neos Dionisos (naos do templo de Debod, na Núbia-Madrid) consagra

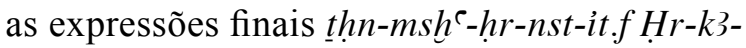
$n h t$, "que desponta na realeza de seu pai, Hórus, touro vitorioso" 31 , o que se conjuga com o que este mesmo faraó, como vimos, convocou para o seu Nome de Hórus ("aquele que se uniu a si próprio com as obras de seu pai, em alegria, aquele que brilha na realeza de seu pai como Hórus").

É possível constatar, igualmente, com relativa curiosidade, que o Nome de Hórus de Ouro de Ptolomeu II Filadelfo recorre à utilização da fórmula sh'i.n-sw it.f, "aquele que surgiu no lugar de seu pai”, que já detectámos nos Nomes das Duas Senhoras de Ptolomeu VI e nos Nomes de Hórus de Ptolomeu IV.

É preciso, todavia, atender que, apesar de ser dos poucos faraós (acompanhado apenas por Ptolomeu XII) que remete tais termos para o seu Nome de Hórus de Ouro, ele é historicamente o primeiro dos Lágidas, como já salientámos, a fazê-los constar de uma titulatura faraónica, ou seja, dito de outra forma, é o primeiro a valorizar a herança paterna do trono do Egipto.

Recorde-se, a propósito, que, como referimos, o Nome de Hórus de Ptolomeu X e o Nome das Duas Senhoras de Ptolomeu IX concedem lugar à variante equivalente shỉi.nsw-mwt.f, "aquele que a sua mãe ..." - a frase continua com "colocou na realeza de seu pai".

26. Apenas escapam a esta regra Ptolomeu II Filadelfo, Cleópatra VII e Ptolomeu XV Cesarião, além, obviamente, de Ptolomeu I Sóter que não recebera a realeza "de seu pai”. Ptolomeu XII, excepcionalmente, convoca referências à sucessão hereditária do poder em três dos seus Nomes do protocolo.

27. Sendo o Nome da titulatura que é antecedido pela designação Hor (Hórus), o Nome de Hórus subentende o faraó como a incarnação do antigo deus da mitologia egípcia, Hórus, filho de Osíris, e é talvez o mais apropriadado para expressar as ideias de transmissão e herança do poder.

28. No $L \ddot{A} I V$ usa-se sempre a transliteração nswit para "realeza", em vez de nsyt como faz Beckerath. Tal regra aplica-se igualmente nos casos do Nome de Hórus de Ptolomeu VIII (frase 5) e dos Nomes de Hórus de Ouro de Ptolomeu IX (Cf. Kurth, 1982: cols. 1194 e 1195).

29. A fraseologia deste Nome de Ptolomeu X concilia criativamente as fórmulas já constatadas em Ptolomeu IV e Ptolomeu VIII.

30. Apenas por confronto com os Argéadas, diga-se que Alexandre IV Aigos, filho de Alexandre Magno, tem um Nome das Duas Senhoras cujo sentido é similar: $r d i$-n.f-ỉwt-n-it.f, "aquele que foi colocado na função de seu pai".

31. Estas expressões não surgem transliteradas por Beckerath, mas são-no por Kurth em $L \ddot{A} I V$, col. 1195, tal como sugere a inscrição hieroglífica in LdR 4: 401, XXX B. 
Atendendo aos Praenomina apresentados, podemos verificar que há, a partir de Ptolomeu III Evérgeta (deixando de fora, portanto, apenas os reinados de Ptolomeu I Sóter, Ptolomeu II Filadelfo e Arsínoe II), um esquema fixo subjacente à composição deste Nome protocolar constituído pela aglutinação de três grandes núcleos significativos ${ }^{32}$ :

$$
i w^{e}-n-n t r w y-\ldots+s t p-n-\ldots+\ldots \text { `nh-(n)-Imn }
$$

O primeiro destes núcleos (iwe-n-ntrwy-..., "o herdeiro dos Deuses ...") admite variações de pormenor relacionadas com a ascendência carnal específica de cada um dos soberanos. As variações são as seguintes:

- iwe-n-ntrwy-snwy, "o herdeiro dos Deuses Irmãos" (Ptolomeu III ${ }^{33}$ );

- iwe-n-ntrwy-mnhwy, "o herdeiro dos Deuses Benfeitores" (Ptolomeu IV, Ptolomeu IX ${ }^{34}$ );

- iwe-n-ntrwy-mr(w)y-it, "o herdeiro dos Deuses que amam o pai” (Ptolomeu V ${ }^{35}$ );

- iwe-n-ntrwy-prwy, "o herdeiro dos Deuses Manifestos" (Ptolomeu VI, Ptolomeu VIII ${ }^{36}$ ).

No caso do faraó Ptolomeu X Alexandre I, o primeiro núcleo não trata os ascendentes em conjunto, como em todos os casos anteriores, optando pelo tratamento individual, mas, no fundo, trata-se do mesmo núcleo significativo: [222] iwe-(n)-ntr-mnh-ntrt-mnht ("o herdeiro do deus benfeitor e da deusa benfeitora") e mry ${ }^{37}-n t r-$ mnh-ntrt-mnht ("o amado do deus benfeitor e da deusa benfeitora").

Também no caso de Ptolomeu IX, três das quatro formas (1, 2 e 3$)$ começam pela expressão

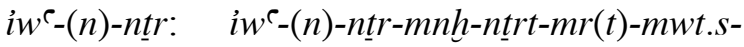
$n \underline{d} t(t)$, "o herdeiro do deus benfeitor e da deusa benfeitora, que ama a sua mãe, o salvador". Trata-se, uma vez mais, de formas relativas ao seu primeiro reinado, como atesta a presença da expressão $m r(t)-m w t . s$, "que ama a sua mãe", numa alusão directa a Cleópatra III.

Da mesma forma, a variante de primeiro núcleo das titulaturas de Ptolomeu XII e de Ptolomeu XV, remetendo apenas para a ascendência masculina, integra-se na mesma lógica conceptual: $i w^{\top}-(n)-p 3-n t r . n t i . n h m$ ("o herdeiro do deus que protege/salva").

Pode ter havido, no caso de Ptolomeu XV, algum embaraço em justificar a sua legitimidade e, por isso, os sacerdotes não lhe atribuíram uma titulatura original, copiando e aplicando pura e simplesmente o Praenomen 2 de Ptolomeu XII, seu avô materno ${ }^{38}$.

Isto significa que podemos, em rigor, indicar três alternativas para o primeiro núcleo:

- iwe-n-ntrwy-..., "o herdeiro dos Deuses ...";

- iwe-(n)-ntr-..., "o herdeiro do deus ..." $\mathrm{e}$

32. Consideramos núcleos significativos as expressões ou frases que o uso tradicional canonizou como vectores obrigatórios da onomástica real egípcia, em geral, e, paulatinamente, em especial, da onomástica lágida.

33. Referência ao casal Ptolomeu II/ Arsínoe II.

34. A forma atribuída a Ptolomeu IX é a do seu segundo reinado, onde não consta o elemento $m r(t) m w t . s$, ("que ama a sua mãe") típico do seu primeiro reinado. No caso de Ptolomeu IV, a designação corresponde ao casal Ptolomeu III/ Berenice II e no caso de Ptolomeu IX a Ptolomeu VIII e Cleópatra III.

35. A designação refere-se a Ptolomeu IV e Arsínoe III.

36. Para ambos os reis, a menção refere-se a Ptolomeu V e Cleópatra I.

37. Neste caso, mry é um sinónimo de i $i w^{e}$.

38. Chauveau, 1997: 62, 63. 
- iwe-(n)-p3-ntr-..., "o herdeiro do deus...".

Quanto ao segundo núcleo (stp-n-..., "o escolhido de ..."), as possibilidades de composição detectadas são as seguintes:

- $\quad s t p-(n)-R R^{\complement}$, “o escolhido de Ré” (Ptolomeu I, Ptolomeu III);

- stp-n-Pth, "o escolhido de Ptah" (Ptolomeu IV, Ptolomeu VI, Ptolomeu VIII, Ptolomeu IX, Ptolomeu X, Ptolomeu XII e Ptolomeu XV);

- stp-n-Pth-Hpri, "o escolhido de Ptah-Khepri" (Ptolomeu VI).

A este segundo núcleo junta-se um complemento que admite também algumas formas distintivas:

- stp-n-... + mry Imn, "o escolhido de ... + o amado de Amon" (Ptolomeu I39);

- $\quad s t p-n-\ldots+w s r-k 3-R$, “o escolhido de ... + poderoso é o ka de Ré" (Ptolomeu IV, Ptolomeu $\mathrm{V})^{40}$;

- stp-n-... + iri-M3't-Rc, "o escolhido de ... aquele que faz reinar a justiça de Amon-Ré" (Ptolomeu VI ${ }^{41}$, Ptolomeu VIII, Ptolomeu IX, Ptolomeu X, Ptolomeu XII ${ }^{42}$ e Ptolomeu XV).

O terceiro núcleo ( ...-`nh-n-Imn, “...- viva de Amon") está ausente no Praenomen de Ptolomeu VI e em duas (de quatro) formas do de Ptolomeu XII. Em todos os outros - Ptolomeu III, Ptolomeu IV, Ptolomeu V, Ptolomeu VIII, Ptolomeu
IX, Ptolomeu X, Ptolomeu XII (uma forma) e Ptolomeu XV - é elemento obrigatório.

Há duas expressões atestadas para introduzir este núcleo: shm e snn. A segunda destas expressões só se constata no Praenomen de Ptolomeu X. Em ambas as formas, o sentido parece ser, não obstante, o mesmo ("imagem"), pelo que, de certa maneira, se podem encarar como sinónimos e considerar o terceiro núcleo dos Praenomina dos Lágidas como o mais "rígido" ou com menos flutuações.

Todas as cambiantes verificadas, mais ou menos ligeiras, relacionadas directamente com a história pessoal de cada soberano ou com (diferentes) associações de divindades do panteão egípcio, não alteram o sentido global deste Nome real. São uma espécie de "nota pessoal", muito ténue, no âmbito de um Nome que é regido por fórmulas de composição rígidas e determinadas.

A análise efectuada da titulatura dos Ptolomeus permite-nos, realmente, destacar a importância conferida pela mentalidade egípcia dos séculos III a I a.C. ao elemento hereditário na transmissão do poder político.

Os sacerdotes-compositores dos Nomes do protocolo, cientes do valor da ascendência-descendência para a legitimação do poder político dos novos reis do país, geneticamente estrangeiros, enfatizam as noções de ligação consanguínea e de filiação como essenciais para a sucessão no poder, recorrendo a vários Nomes e a várias fórmulas-tipo, como sejam a evocação

39. Embora não partilhe dos três núcleos típicos do Praenomen que aqui tratamos, Ptolomeu I foi, porém, o primeiro a incorporar a unidade $s t p-n-R^{\complement}$ no seu Nome de Trono.

40. Entre os Lágidas, a unidade $w s r-k 3-R^{e}$ foi usada pela primeira vez por Ptolomeu II.

41. No caso deste faraó, o complemento exacto introduz uma pequena variação: irí-M3`t-Imn-R ${ }^{\complement}$. Talvez devido a esta pecularidade, D. Kurth prefere apresentar a expressão como iri-m $3^{\complement} t-R^{\top}-$-Imn, numa inversão bizarra da corrente designação “Amon-Ré” (Cf. Kurth, 1982: col. 1194).

42. Para Ptolomeu XII, em dois dos seus quatro Praenomina encontram-se também duas ligeiríssimas "nuances", aqui

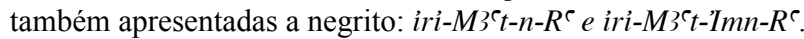


da realeza recebida "de seu pai" (it.f) ou "de sua mãe" (mwt.f), patente nos Nomes de Hórus, ou o núcleo significativo $i w^{\top}-n-\ldots$, "o herdeiro de ...", com abundantes exemplos nos Praenomina.

Também os Nomes de Hórus de Ouro (como é exemplar o caso de Ptolomeu II Filadelfo, historicamente o primeiro lágida a valorizar a herança paterna do trono do Egipto e a fazê-lo figurar na onomástica real, através da fórmula sh'i.n-sw it.f, "aquele que surgiu no lugar de seu pai") ou dos Nomes das Duas Senhoras (como se verifica com Ptolomeu VI, que reaproveita a fórmula do Nome de Hórus de Ouro de Ptolomeu II) colaboraram, embora com menor número de referências e de faraós a usarem estes Nomes, no destaque conferido à noção da transmissão hereditária da realeza.

É preciso recordar que durante o período ptolomaico a ideia da transmissão hereditária da realeza se estendeu inclusive ao próprio Alexandre Magno. A tradição lendária que envolve o último faraó autóctone é-nos igualmente acessível quer pela Crónica Demótica (conjunto de oráculos obscuros e suas interpretações, datada do séc. III a.C.), quer por um fragmento de papiro datado do séc. II a.C., traduzido de demótico para grego, o Somnium Nectanebi, quer pela lenda arménia sobre o nascimento de Alexandre, quer, sobretudo, pelo Romance de Alexandre do Pseudo-Calístenes, que marcará todo o período medieval. Todas estas fontes dão grande ênfase às narrativas que estabelecem uma artificiosa ligação linhagística entre o último faraó egípcio autóctone Nakhthorheb (Nectanebo II), descrito como sacerdote perito em artes mágicas e em prever o futuro por meio da lecanomancia ${ }^{43}$ e o seu pretenso filho e de Olimpíade, que, entretanto, seduzira. Assimilado ao deus Amon (de quem manteve a suave pele e os chifres, embora tivesse adoptado a forma de uma serpente ou de um dragão) Nectanebo fez de Alexandre filho de Amon. A lenda dá a Alexandre um (novo) pai e a herança do trono do Egipto. O oráculo de Siuah apenas confirmaria esta vertente lendária da filiação ${ }^{44}$.

A necessidade absoluta de verosimilhança histórica destes traços "familiares" faz com que no caso dos Ptolomeus, em contraste com a situação de Alexandre Magno, a maioria das fórmulas ou núcleos analisados sejam alusões a situações históricas precisas e determinadas. É um exemplo de um segmento da construção ideológica em que a realidade vem em auxílio da idealização.

Aquilo que um faraó era ou pretendia ser manifestava-se nos títulos e Nomes que escolhia e usava. "Ser rei" no Egipto ptolomaico é, sob muitos aspectos, o resultado directo de ser "filho/herdeiro de reis", tanto no plano físico como metafísico.

O que é extraordinário no caso dos Ptolomeus e digno de realce são a forte presença da noção da sucessão/herança nos seus Nomes e a ênfase que os seus protocolos conferem à questão da hereditariedade carnal como vector essencial na transmissão do poder. Esta é a mais importante diferença e característica do protocolo dos Ptolomeus em relação aos nomes de outros faraós do Egipto antigo. 


\section{Bibliografia}

AufrÈre, S.

1982 Contribution à l'étude de la morphologie du protocole "classique", BIFAO 82: 19-73.

BARTA, W.

1989 Zur Konstruktion der äegyptischen Königsnamen, Z̈̈S 116: 4-9, 11-137.

BECKERATH, J. VON

1984 Handbuck der Ägyptischen Königsnamen, $M \ddot{A} S$ 20. München.

1999 Handbuck der Ägyptischen Königsnamen, MÄS 49. München.

BonHÈME, M.-A.

1987 Les noms royaux dans l'Égypte de la Troisième Période Intermédiaire. Le Caire.

Chauveau, $\mathrm{M}$.

1997 L'Égypte au temps de Cléopâtre. 180-30 av $J .-C$. Paris.

Dobrev, V.

1993 Considérations sur les titulatures des rois de la IVe dynastie égyptienne, BIFAO 93: 179204.

GAUTHIER, H.

1907 Le Livre des Rois 4. Époque Macedo-grecque. Recueil de titres et protocoles royaux, noms propres de rois, reines, princes et princesses, noms de pyramides et de temples solaires, suivi d'un index alphabétique. Le Caire.

GRENIER, J.-CL.

1987 Le protocole pharaonique des empereurs romains (Analyse formelle et signification historique), RdE 38: 81-104.

1989 Les titulatures des empereurs romains dans les documents en langue égyptienne. Bruxelles.
HölBL, G.

2001 A History of the Ptolemaic Empire. London, New York.

Husson, G.; Valbelle D.

1992 L'état et les institutions en Égypte. Des premiers pharaons aux empereurs romains. Paris.

KaPLONy, P.

1980 Königstitulatur, LÄ III: col. 641- 659.

KURTh, D.

1982 s.u. Ptolemaios, $L \ddot{A} I V$ : cols. 1193-1197.

LEPROHON, R. J.

1996 The programmatic use of the royal titulary in the twelfth dynasty, JARCE 33: 165-171.

Menu, B.

1995a Le tombeau de Pétosiris (4). Le souverain de l'Egypte, BIFAO 98: 247-262.

1995b Alexandre le Grand, $h k 3 n k m t$, BIFAO 99: 353-356.

Meulenaere, H. DE

1991 Le protocole royal de Philippe Arrhidée, Mélanges Jacques-Jean Clère. CRIPEL 13. Papyrologie. Archèologie: 53-58.

PARENT, F.

1992 Seth dans l'Horus d'or des titres royaux, in Obsomer, Cl. (ed.): Amosiadès. Mèlanges offerts au Professeur Claude Vandersleyen par ses anciens étudiants, Louvain-la-Neuve: 347-354.

Sales, J. C.

2005 Ideologia e propaganda real no Egipto Ptolomaico (305-30 a.C.). Lisboa. 
SCHNEIDER, T.

1996 Lexikon der pharaonen. München.

Serrano Delgado, J. M.

2001 La titulatura real de los faraones persas, in Cervelló-Autuori, J.; Quevedo Álvarez, A. J. (eds.): ... Ir a buscar leña. Estudios dedicados al Prof. Jesús López, (Aula Aegyptiaca. Studia 2), Barcelona: 175-184.
SpIESER, C.

2000 Les noms du Pharaon comme êtres autonomes au Nouvel Empire. (OBO 70). Freiburg (Schweiz) / Göttingen.

VAlbelle, D.

1998 Histoire de l'État pharaonique. Paris. 


\section{Trabajos de Egiptología Papers on Ancient Egypt}

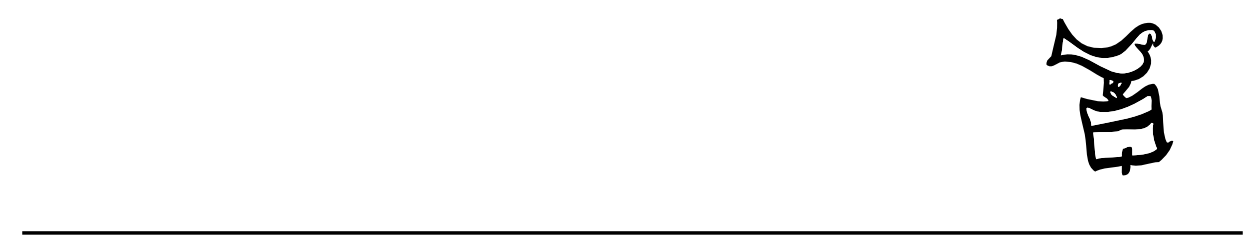

Número 5/2 2009 


\section{Actas \\ III Congreso Ibérico de Egiptología III Congresso Ibérico de Egiptologia}

Editores

Miguel Ángel Molinero Polo Covadonga Sevilla Cueva 


\title{
Editor
}

Miguel Ángel Molinero Polo

Universidad de La Laguna

\section{Consejo Editorial}

\author{
Antonio Pérez Largacha \\ Universidad de Castilla-La Mancha \\ José-R. Pérez-Accino \\ Birkbeck, Universidad de Londres \\ Covadonga Sevilla Cueva \\ Universidad Autónoma de Madrid
}

\section{Comité Científico}

Josep Cervelló i Autuori

Universitat Autònoma de Barcelona

$\mathrm{M}^{\mathrm{a}}$ José lópez Grande

Universidad Autónoma de Madrid

Josep Padró i Parcerisa

Universitat de Barcelona

$\mathrm{M}^{\mathrm{a}}$ Carmen Pérez Die

Museo Arqueológico Nacional, Madrid

Ester Pons Mellado

Museo Arqueológico Nacional, Madrid

José M. Serrano Delgado

Universidad de Sevilla

\section{Colaboradores Editoriales}

Linda Steynor

English editorial assistant

Hervé Mouriacoux

Assistant éditorial pour la langue française 
Trabajos de Egiptología está producida por Isfet. Egiptología e Historia c/ Blanco $1,2^{\circ}$

38400 Puerto de la Cruz

Tenerife-Islas Canarias

España

Maquetación: Proyecto Limón

(C) Autores de los artículos aparecidos

y Consejo Editorial de Trabajos de Egiptología - Papers on ancient Egypt

Depósito Legal: TF-2303-2009

ISSN: $1695-4750$

Imprime: Gráfica Los Majuelos, S.L.L.

imprenta@graficaslosmajuelos.com

Tfno.: 922311455 


\section{Comité Científico \\ III Congreso Ibérico de Egiptología III Congresso Ibérico de Egiptologia}

Miguel Á. Molinero Polo

Universidad de La Laguna

Presidente del Comité Organizador del III Congreso Ibérico de Egiptología

Miembro del Comité Organizador del I Encuentro de Egiptología

Josep Cervelló Autuori

Universitat Autònoma de Barcelona

Presidente del Comité Organizador del II Congreso Ibérico de Egiptologia

José Manuel Galán Allué

Consejo Superior de Investigaciones Cientificas

Director del Proyecto Djehuty, Luxor, Egipto

$\mathrm{M}^{\mathrm{a}}$ Helena Trindade Lopes

Universidad de Lisboa

Directora de la Misión Arqueológica Portuguesa en Menfis

Josep Padró i Parcerisa

Universitat de Barcelona

Director de la Misión Arqueológica de Oxirrinco

Antonio Pérez Largacha

Universidad de Castilla - La Mancha

Miembro del Comité Organizador del I Encuentro de Egiptología

José Ramón Pérez-Accino

Birkbeck College, University of London

Miembro del Comité Organizador del I Encuentro de Egiptología

$\mathrm{M}^{\mathrm{a}}$. Carmen Pérez Díe

Museo Arqueológico Nacional

Directora de la Misión Arqueológica Española en Heracleópolis Magna, Egipto

Covadonga Sevilla Cueva

Universidad Autónoma de Madrid

Miembro del Comité Organizador del I Encuentro de Egiptología 